\title{
Thermotropic phase behavior and headgroup interactions of the nonbilayer lipids phosphatidylethanolamine and monogalactosyldiacylglycerol in the dry state
}

\author{
Antoaneta V Popova ${ }^{1,2}$ and Dirk K Hincha ${ }^{1 *}$
}

\begin{abstract}
Background: Although biological membranes are organized as lipid bilayers, they contain a substantial fraction of lipids that have a strong tendency to adopt a nonlamellar, most often inverted hexagonal $\left(H_{\|}\right)$phase. The polymorphic phase behavior of such nonbilayer lipids has been studied previously with a variety of methods in the fully hydrated state or at different degrees of dehydration. Here, we present a study of the thermotropic phase behavior of the nonbilayer lipids egg phosphatidylethanolamine (EPE) and monogalactosyldiacylglycerol (MGDG) with a focus on interactions between the lipid molecules in the interfacial and headgroup regions.

Results: Liposomes were investigated in the dry state by Fourier-transform Infrared (FTIR) spectroscopy and Differential Scanning Calorimetry (DSC). Dry EPE showed a gel to liquid-crystalline phase transition below $0^{\circ} \mathrm{C}$ and a liquid-crystalline to $\mathrm{H}_{\|}$transition at $100^{\circ} \mathrm{C}$. MGDG, on the other hand, was in the liquid-crystalline phase down to $-30^{\circ} \mathrm{C}$ and showed a nonbilayer transition at about $85^{\circ} \mathrm{C}$. Mixtures ( $1: 1$ by mass) with two different phosphatidylcholines (PC) formed bilayers with no evidence for nonbilayer transitions up to $120^{\circ} \mathrm{C}$. FTIR spectroscopy revealed complex interactions between the nonbilayer lipids and PC. Strong H-bonding interactions occurred between the sugar headgroup of MGDG and the phosphate, carbonyl and choline groups of PC. Similarly, the ethanolamine moiety of EPE was $\mathrm{H}$-bonded to the carbonyl and choline groups of PC and probably interacted through charge pairing with the phosphate group.

Conclusions: This study provides a comprehensive characterization of dry membranes containing the two most important nonbilayer lipids (PE and MGDG) in living cells. These data will be of particular relevance for the analysis of interactions between membranes and low molecular weight solutes or soluble proteins that are presumably involved in cellular protection during anhydrobiosis.
\end{abstract}

\section{Background}

Biological membranes are composed of a wide range of lipids with different physicochemical properties. While the major components are usually bilayer forming lipids, most cellular membranes also contain a significant complement of lipids that can adopt nonbilayer structures such as an inverted hexagonal phase $\left(\mathrm{H}_{\mathrm{II}}\right)[1,2]$. Some biologically important functions such as membrane fusion $[3,4]$ are related to formation of $\mathrm{H}_{\text {II }}$ structures.

\footnotetext{
* Correspondence: hincha@mpimp-golm.mpg.de

'Max-Planck-Institut für Molekulare Pflanzenphysiologie, Am Mühlenberg 1,

D-14476 Potsdam, Germany

Full list of author information is available at the end of the article
}

Therefore, the formation of $\mathrm{H}_{\text {II }}$ has been the subject of considerable interest and different molecular models have been developed that reflect the physical and chemical properties governing the transition from lamellar to $\mathrm{H}_{\text {II }}$ phase [5-7]. The transition dependends on different internal (molecular shape, degree of unsaturation and length of the fatty acyl chains, charge and hydration of the headgroup) and external factors (water content, temperature, $\mathrm{pH}$, ionic strength, solutes) [6-10]. In addition, $\mathrm{H}$-bonding between lipid molecules also contributes to their phase behavior [11].

Cellular membranes are primary sites of damage during environmental stresses such as freezing or drying. In

\section{Ciomed Central}


addition, membrane stability can be compromised during technical biopreservation procedures such as cell or organ cryopreservation, or the preparation of dry biomaterials for long-term storage. Liposomes have been used for many years as convenient model systems to study the effects of membrane lipid composition and soluble protectants such as sugars on membrane stability during drying in the context of anhydrobiosis in microbes, animals and plants, and the development of improved biopreservation protocols (see [12-14] for reviews).

Lipid composition, especially the presence of the nonbilayer lipids phosphatidylethanolamine (PE) and monogalactosyldiacylglycerol (MGDG), can strongly influence membrane stability during dehydration and the efficiency of amphiphilic small molecules [15-17] and soluble plant stress proteins $[18,19]$ to stabilize membranes. It is therefore important to investigate the phase behavior and interactions between lipids in dry membranes containing either only nonbilayer lipids or mixtures of nonbilayer and bilayer lipids to better understand the effects of such protectants on membrane structure and their interactions with the membrane surface. Anhydrous systems are of particular utility for such studies, as they allow the unambiguous identification of molecular interactions without the interfering effects of water. Obviously, once the anhydrous system has been thoroughly characterized, it will be possible to systematically investigate the contributions of small amounts of water in partitially dehydrated samples, as they will often occur under natural conditions.

$\mathrm{PE}$ is one of the most abundant lipids in cellular membranes and can form either lamellar or nonlamellar phases. Increasing temperatures lead to a transition from the gel to the liquid-crystalline phase, followed by a transition to $\mathrm{H}_{\mathrm{II}}$ in the fully hydrated state. However, also direct gel to $\mathrm{H}_{\mathrm{II}}$ transitions without an intermediate liquid-crystalline phase have been reported [2,7]. Differential Scanning Calorimetry (DSC) experiments have shown that the transition from gel to liquid-crystalline state is highly cooperative and strongly endothermic, while the transition from liquid-crystalline to $\mathrm{H}_{\mathrm{II}}$ has a low enthalpy [7] indicating that the acyl chains of the lipids in nonbilayer conformation are not markedly more disordered than in the liquidcrystalline state of the bilayer [20].

Mixing PE with bilayer lipids such as phosphatidylcholine (PC) favours the formation of bilayers [1]. The stability of these mixed bilayers depends on the ratio between bilayer and nonbilayer lipids [20-22]. Generally, it is assumed that the ability of PC to stabilize bilayers containing $\mathrm{H}_{\mathrm{II}}$ lipids is a consequence of the phase preference of $\mathrm{PC}$ rather than the result of specific interactions between PC and PE [2].

The most abundant polar lipid on Earth is MGDG. It comprises about $50 \%$ of the total lipid content of photosynthetic membranes in higher plants and algae and is, like PE, a nonbilayer lipid [23-25]. Hydrated MGDG from the leaves of higher plants forms nonbilayer phases over a wide temperature range of approximately $-15^{\circ} \mathrm{C}$ to $80^{\circ} \mathrm{C}$ [26-28]. Similar to PE, MGDG can be stabilized in lamellar structures when mixed with PC $[29,30]$.

$\mathrm{H}_{\mathrm{II}}$ formation in membranes can be induced by dehydration, either through the removal of water or the additon of osmolytes [22,31-36]. These reports concern mainly the phase behavior of lipids at different degrees of hydration. However, no studies have specifically focused on mixed membranes composed of bilayer and nonbilayer lipids in the dry state and in particular on the interactions between the lipids. We therefore investigated the thermotropic phase behavior of dry membranes containing egg PE (EPE) or MGDG by FTIR spectroscopy and DSC. The focus of our work was on the FTIR studies that allowed us to investigate the interactions between the different lipids to evaluate the contributions of headgroup interactions to the phase behavior of dry membranes.

\section{Methods}

\section{Liposome preparation}

Egg PC (EPC, fatty acid composition: 32.7\% 16:0, 12.3\% $18: 0,32.0 \% 18: 1,17.1 \% 18: 2$ ) and 1,2 dimyristoyl-sn-glycero-3-phosphocholine (DMPC, 100\% 14:0) were obtained from Avanti Polar Lipids (Alabaster, AL, http:// www.avantilipids.com). The chloroplast galactolipid MGDG (fatty acid composition: $21.5 \%$ 16:0, 5.7\% 18:0, 6.0\% 18:1, 64.5\% 18:3) from spinach leaves and EPE (fatty acid composition: $22.0 \%$ 16:0, 37.4\% 18:0, 29.4\% 18:1, 11.2\% 18:2) were purchased from Lipid Products (Redhill, Surrey, UK, http://lipidproducts.virtualave.net).

To make the results from the present study comparable to studies on the effects of various solutes and proteins on membranes in the dry state, we used extruded liposomes wherever possible. Lipids (10 mg of pure lipids or binary mixtures at a 1:1 mass ratio) were dried from chloroform under a stream of $\mathrm{N}_{2}$ and subsequently under vacuum over night. The resulting lipid film was hydrated in $200 \mu \mathrm{l}$ of distilled water and liposomes were formed using a hand-held extruder (Avestin, Ottawa, Canada) with two layers of $100 \mathrm{~nm}$ pore filters [37].

\section{Fourier-transform infrared (FTIR) spectroscopy}

Liposomes $(50 \mu \mathrm{l})$ were spread on $\mathrm{CaF}_{2}$ windows and dried at $0 \%$ relative humidity in desiccators at $28^{\circ} \mathrm{C}$ for 6 to 8 hours in the dark and then kept over night under vacuum. Since pure EPE or MGDG do not form bilayers, $2.5 \mathrm{mg}$ lipids in chloroform were spread directly on $\mathrm{CaF}_{2}$ windows, the solvent was evaporated under a stream of $\mathrm{N}_{2}$ and then under vacuum over night. FTIR measurements were performed with a Perkin-Elmer GX 2000 spectrometer as described in detail previously [38,39]. A window with the dry sample was placed in a cuvette 
holder, fixed in a vacuum chamber connected to a temperature control unit (Specac Eurotherm, Worthington, UK) and placed in the infrared beam. Temperature was monitored by a fine thermocouple fixed on the window next to the sample. Samples were kept in the sample holder under vacuum at $30^{\circ} \mathrm{C}$ for $30 \mathrm{~min}$ to remove residual moisture absorbed during handling. This was verified by the absence of a water band in the FTIR spectra at $1650 \mathrm{~cm}^{-1}$. In addition, the position of the $v \mathrm{P}=\mathrm{O}$ as band of PC above $1260 \mathrm{~cm}^{-1}$ indicated that the samples were essentially anhydrous [40]. Temperature was then decreased to $-30^{\circ} \mathrm{C}$ and after 10 min equilibration, the temperature was increased at a rate of $1^{\circ} \mathrm{C} \mathrm{min}{ }^{-1}$. Two spectra were recorded and coadded every minute. Spectra were analyzed using Spectrum 5.0.1 software. After normalization of absorbance and baseline correction of the spectra by the interactive abex and flat routines, the wavenumbers of the symmetric $\mathrm{CH}_{2}$ stretching vibration $\left(v \mathrm{CH}_{2} \mathrm{~s}\right), \mathrm{C}=\mathrm{O}$ stretching vibration $(v \mathrm{C}=\mathrm{O})$, asymmetric $\mathrm{P}=\mathrm{O}$ stretching vibration $(v \mathrm{P}=\mathrm{Oas})$, sugar $\mathrm{OH}$ stretching vibration $(\mathrm{vOH})$ and asymmetric choline stretching vibration $\left(v \mathrm{~N}^{+}\left(\mathrm{CH}_{3}\right)_{3}\right.$ as $)$ bands were determined by the peak identification routine. These peaks cover all relevant functional groups in the investigated lipids. The gel to liquid-crystalline phase transition temperature $\left(\mathrm{T}_{\mathrm{m}}\right)$ was determined as the midpoint of the shift in $\mathrm{vCH}_{2} \mathrm{~S}$ with temperature [41]. The carbonyl stretching peak $(v \mathrm{C}=\mathrm{O})$ between $1770 \mathrm{~cm}^{-1}$ and $1700 \mathrm{~cm}^{-1}$ was analyzed by peak deconvolution and curve fitting using the peak-fitting module of OriginPro 7.0 as described in detail previously $[40,42]$. Correlation coefficients for all fitted curves were higher than 0.999 .

\section{Differential scanning calorimetry (DSC)}

Liposomes $(50 \mu \mathrm{l})$ or $2.5 \mathrm{mg}$ of EPE or MGDG in chloroform were applied to aluminium pans and dried as described for the FTIR samples. Earlier measurements had shown that such samples contained less than $0.02 \mathrm{~g}$ $\mathrm{H}_{2} \mathrm{O} / \mathrm{g}$ lipid [40]. Pans were sealed in a glove bag under $\mathrm{N}_{2}$ atmosphere and transferred directly into a Netzsch (Selb, Germany) DSC 204. Samples were cooled to $-70^{\circ}$ $\mathrm{C}$ and then heated to $120^{\circ} \mathrm{C}$ with 5 min of equilibration at the lowest and highest temperature. Cooling and heating scans were performed three times at a rate of $20^{\circ} \mathrm{C} \mathrm{min}^{-1}$ with each sample and at least three samples were measured. Analysis of the thermograms was performed using the Netzsch software package. The phase transition temperatures (gel to liquid-crystalline $\left(\mathrm{T}_{\mathrm{m}}\right)$ or bilayer to nonbilayer $\left(\mathrm{T}_{\text {hex }}\right)$ ) were determined as the temperature at the peak maximum of the second heating scan. The enthalpy change of the phase transitions $(\Delta \mathrm{H})$ was obtained from the areas under the peaks of the transitions.

\section{Results}

\section{Phase behavior of the dry lipids}

Figure 1 shows the melting curves of dry EPE and MGDG and of the respective 1:1 mixtures of the two nonbilayer lipids with either EPC or DMPC, as determined by FTIR spectroscopy. For comparison the melting curves of dry liposomes containing pure EPC or DMPC are also included in Figure 1A. The temperature induced increase in $\mathrm{vCH}_{2} \mathrm{~S}$ indicates the increase in conformational disorder of the hydrocarbon chains associated with chain melting [43].

As expected for a fully saturated lipid, dry DMPC liposomes showed the highest $\mathrm{T}_{\mathrm{m}}\left(84^{\circ} \mathrm{C}\right)$ of all investigated samples. The $\mathrm{T}_{\mathrm{m}}$ of dry EPC, which mainly contains monounsaturated POPC, was more than $40^{\circ} \mathrm{C}$ lower, in agreement with our earlier measurements [39]. The $\mathrm{T}_{\mathrm{m}}$ of dry EPE was again almost $40^{\circ} \mathrm{C}$ lower than that of EPC. Interestingly, while the $T_{m}$ of a 1:1 mixture of EPE and DMPC was at the mid-point between the $T_{m}$ values of the pure lipids, a mixture of EPE and EPC showed the same melting behavior as pure EPE (Figure 1A). The

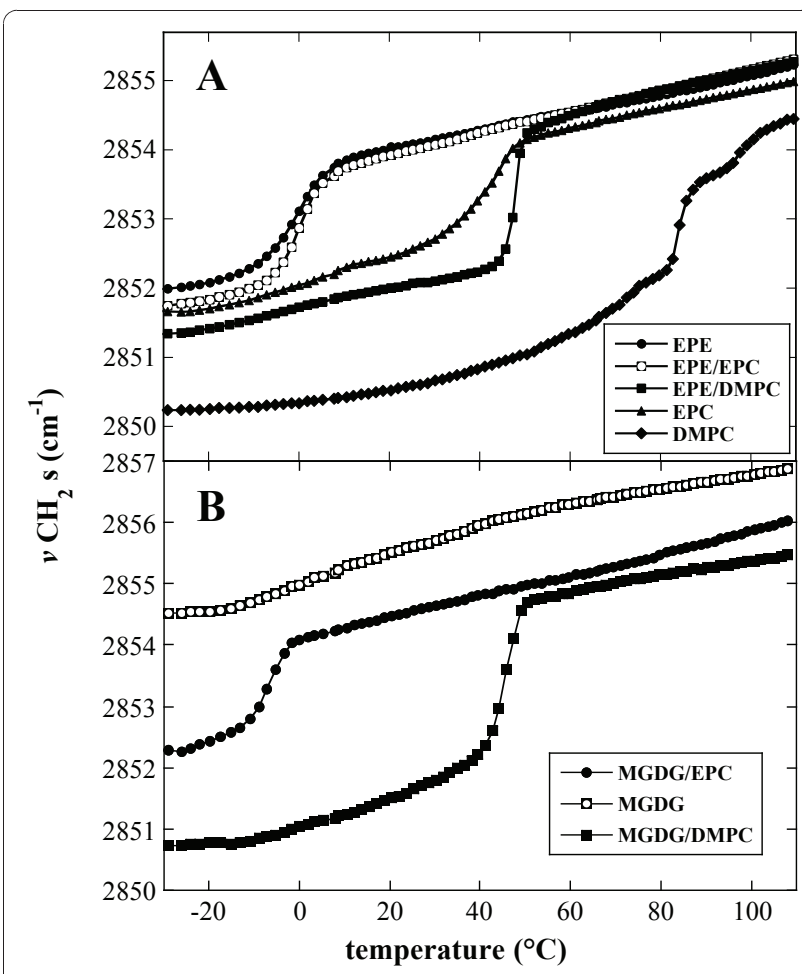

Figure 1 Lipid melting curves determined as the temperature dependent increase in the position of the $\mathrm{CH}_{2}$ symmetric stretching vibration band $\left(\mathrm{vCH}_{2} \mathrm{~s}\right)$ of the fatty acyl chains in FTIR spectra. Samples contained either the pure lipids or binary lipid mixtures at a 1:1 mass ratio as indicated in the panels. Phase transition temperatures $\left(T_{m}\right)$ were determined as the midpoints of the melting curves and are shown in Table 1. 
$v \mathrm{CH}_{2} \mathrm{~S}$ of all lipid samples except for DMPC were very similar, while DMPC showed consistently lower values, especially in the gel state, indicating tighter chain packing of saturated fatty acids.

$v \mathrm{CH}_{2} \mathrm{~s}$ of MGDG was above $2854 \mathrm{~cm}^{-1}$ at all temperatures with a gradual increase during heating, indicating a high degree of disorder typical for both the liquidcrystalline and nonbilayer phases (Figure 1B). Since these phases are characterized by a high degree of disorder in the fatty acid chains, they can not be distinguished by FTIR [44]. Binary mixtures of MGDG with EPC or DMPC showed well defined phase transitions, presumably from gel to liquid-crystalline state. In the gel phase $\mathrm{vCH}_{2} \mathrm{~S}$ of MGDG/EPC was higher than for MGDG/DMPC liposomes in accordance with the differences in unsaturation.

For all melting curves in Figure 1, except for MGDG, the values of $v_{C_{2}} \mathrm{~S}$ at low temperatures are indicative of lipids in the gel phase. At high temperatures $\mathrm{vCH}_{2} \mathrm{~s}-$ values could either indicate lipids in the liquid-crystalline or in a nonlamellar phase. In addition, liquid-crystalline to nonlamellar phase transitions may have occurred that were not detectable by FTIR.

DSC measurements were performed to obtain a more complete picture of the phase behavior of the different lipids in the dry state (Figure 2). Fully hydrated PE and MGDG tend to arrange in nonlamellar structures such as cubic or $\mathrm{H}_{\text {II }}$ phase, depending on temperature and fatty acid composition [9,26,45-48]. While in the fully hydrated state transitions often proceed from liquidcrystalline through a cubic intermediate to the $\mathrm{H}_{\mathrm{II}}$

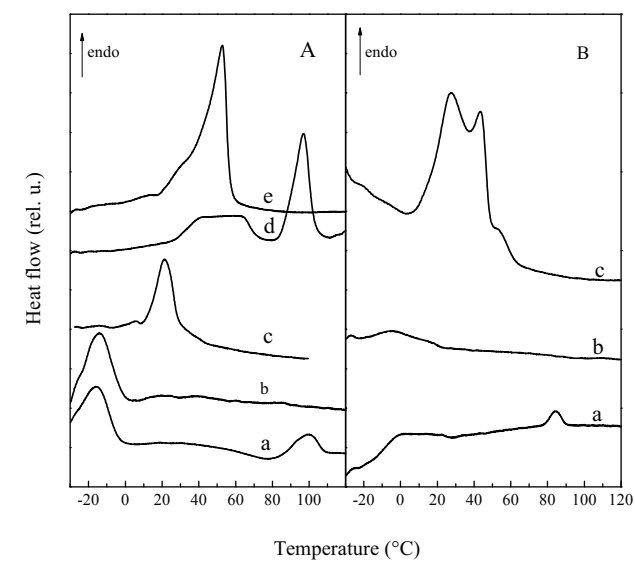

Figure 2 DSC heating thermograms of dry samples. Panel (A) shows data for pure EPE (a) and for dry liposomes containing 50\% EPE/50\% EPC (b), pure EPC (c), pure DMPC (d) and 50\% EPE/50\% DMPC (e). Panel (B) shows data for dry pure MGDG (a) and for dry liposomes containing 50\% MGDG/50\% EPC (b) and 50\% MGDG/50\% DMPC (c). Thermograms are from the second heating scan from $-30^{\circ} \mathrm{C}$ to $120^{\circ} \mathrm{C}$. Phase transition temperatures $\left(T_{m}\right.$ and $\left.T_{\text {hex }}\right)$ and transition enthalpies $(\Delta \mathrm{H})$ are shown in Table 1. phase, reduced water content favours a direct transition from the lamellar to the $\mathrm{H}_{\text {II }}$ phase [49].

In the dry state EPE showed two phase transitions, the first at $-15^{\circ} \mathrm{C}$ corresponding to the chain melting transition from gel to liquid-crystalline, followed by a low enthalpy transition at $100^{\circ} \mathrm{C}$, attributed to a bilayer to $\mathrm{H}_{\mathrm{II}}$ transition (Figure 2A). For dry MGDG only one transition with low enthalpy at $85^{\circ} \mathrm{C}$ was observed (Figure 2B). These two thermograms indicate that EPE proceeded from gel through liquid-crystalline to $\mathrm{H}_{\mathrm{II}}$ phase during heating, while dry MGDG was only in either the liquid-crystalline or nonbilayer phase in the investigated temperature range. In all other samples, only transitions from gel to liquid-crystalline phase were observed. The transition temperatures and associated enthalpies are shown in Table 1 in comparison to the corresponding $\mathrm{T}_{\mathrm{m}}$ values determined by FTIR. The transition temperatures determined by DSC were lower than those determined by FTIR. We attribute this to residual water the samples may have absorbed during handling. Such water was removed in the FTIR experiments because the samples were kept under vacuum before and during the measurements. These differences, however, were consistent between different lipid samples and do not invalidate our conclusions regarding the lipid phase behavior.

\section{$\mathrm{H}$-bonding interactions of the carbonyl ester groups}

The carbonyl ester $(\mathrm{C}=\mathrm{O})$ groups of diacylglycerolipids reside in the interfacial region of the lipid bilayer and are potential participants in H-bonding interactions with water or with other functional groups of the same or different lipid molecules. The $\mathrm{C}=\mathrm{O}$ groups give rise to a major peak in the infrared spectra of lipids at around $1738 \mathrm{~cm}^{-1}$ that is sensitive to the polarity of and interactions with the local environment. The $\mathrm{C}=\mathrm{O}$ peak can be resolved into two underlying peaks. The higher wavenumber component band at $1742 \mathrm{~cm}^{-1}$ arises from free (i.e. not $\mathrm{H}$-bonded) $\mathrm{C}=\mathrm{O}$ groups, while the downfield component band at $1726 \mathrm{~cm}^{-1}$ originates from $\mathrm{C}=\mathrm{O}$ groups involved in $\mathrm{H}$-bonding [50-52]. The analysis of $\mathrm{C}=\mathrm{O}$ peaks was performed either at $90^{\circ} \mathrm{C}$ (all lipid compositions except pure DMPC) or at $100^{\circ} \mathrm{C}$ (pure DMPC) as at these temperatures the lipids were in a stable liquid-crystalline state.

Figure 3 shows the $\mathrm{C}=\mathrm{O}$ contours of all dry samples that were also analyzed for their melting behavior (Figures 1 and 2). The $\mathrm{C}=\mathrm{O}$ contour of pure EPE is centered at $1740 \mathrm{~cm}^{-1}$, while all other peaks are located several wavenumbers lower. The peak measured with pure MGDG is broadened on the downfield side and those from liposomes containing MGDG/EPC or MGDG/DMPC show indications of component peaks attributable to free and $\mathrm{H}$-bonded $\mathrm{C}=\mathrm{O}$ (Figure $3 \mathrm{~B}$ ). 
Table 1 Effects of composition on the lipid melting behavior.

\begin{tabular}{|c|c|c|c|c|c|}
\hline Sample composition & $\mathrm{T}_{\mathrm{m}}\left({ }^{\circ} \mathrm{C}\right)(\mathrm{FTIR})$ & $\begin{array}{c}\mathrm{T}_{\mathrm{m}}\left({ }^{\circ} \mathrm{C}\right) \\
\text { (DSC) }\end{array}$ & $\begin{array}{c}\mathrm{T}_{\text {hex }}\left({ }^{\circ} \mathrm{C}\right) \\
\text { (DSC) }\end{array}$ & $\begin{array}{c}\Delta \mathrm{H} \mathrm{T}_{\mathrm{m}} \\
(\mathrm{kJ} / \mathrm{mol})\end{array}$ & $\begin{array}{l}\Delta \mathrm{H} \mathrm{T}_{\text {hex }} \\
(\mathrm{kJ} / \mathrm{mol})\end{array}$ \\
\hline $100 \%$ EPE & -3.4 & -14.9 & 100.4 & 10.30 & 3.79 \\
\hline 50\% EPE/50\% EPC & 0.0 & -14.0 & & 16.67 & \\
\hline $50 \%$ EPE/50\% DMPC & 47.5 & 53.0 & & 32.03 & \\
\hline $100 \%$ EPC & 39.6 & 22.0 & & 27.20 & \\
\hline $100 \%$ DMPC & 84.3 & 97.6 & & 23.20 & \\
\hline $100 \%$ MGDG & & & 84.7 & & 0.96 \\
\hline $50 \%$ MGDG/50\% EPC & -9.0 & & & & \\
\hline $50 \%$ MGDG/50\% DMPC & 44.5 & $27.6 / 43.6$ & & 36.70 & \\
\hline
\end{tabular}

Values for phase transition temperatures $\left(T_{m}\right)$ were either determined by FTIR (Fig. 1) or DSC (Fig. 2). Bilayer to hexagonal phase transition temperatures ( $T_{\text {hex }}$ ) and transition enthalpies $(\Delta \mathrm{H})$ were determined by DSC

For a quantitative analysis of the interactions of the $\mathrm{C}=\mathrm{O}$ groups, the peak was deconvoluted into its two component bands centered at $1742 \mathrm{~cm}^{-1}$ and $1728 \mathrm{~cm}^{-1}$. The relative area of the band components is proportional

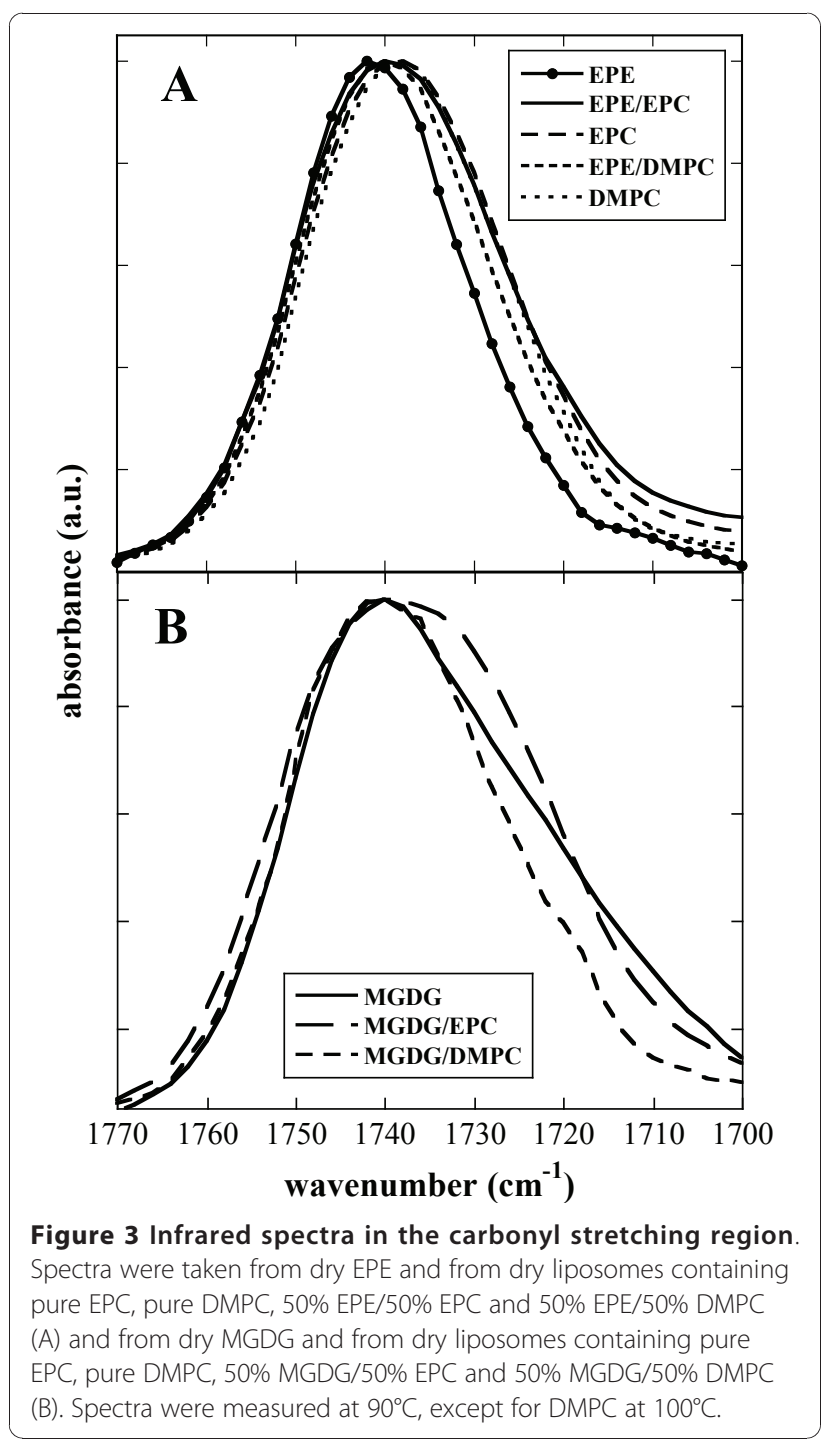

to the number of free and $\mathrm{H}$-bonded $\mathrm{C}=\mathrm{O}$ groups $[40,42,53]$. The ratio of the two component bands changes with changes in lipid composition. Since in our FTIR experiments the lipids are essentially anhydrous, the $\mathrm{H}$-bonding observed in all samples must derive almost exclusively from interactions between different lipid molecules. For dry EPC liposomes the ratio A $\mathrm{C}=\mathrm{O}_{\mathrm{H} \text {-bonded }} / \mathrm{A} \mathrm{C}=\mathrm{O}_{\text {free }}$ was 0.7 (Figure 4), indicating that the population of free $\mathrm{C}=\mathrm{O}$ groups was higher than that of $\mathrm{H}$-bonded $\mathrm{C}=\mathrm{O}$ groups. We have presented evidence previously [40] that the most likely $\mathrm{H}$-bonding interaction partners for $\mathrm{C}=\mathrm{O}$ groups in dry $\mathrm{EPC}$ membranes are the choline groups of neighbouring lipid molecules. In dry DMPC $\mathrm{H}$-bonding to $\mathrm{C}=\mathrm{O}$ groups was less

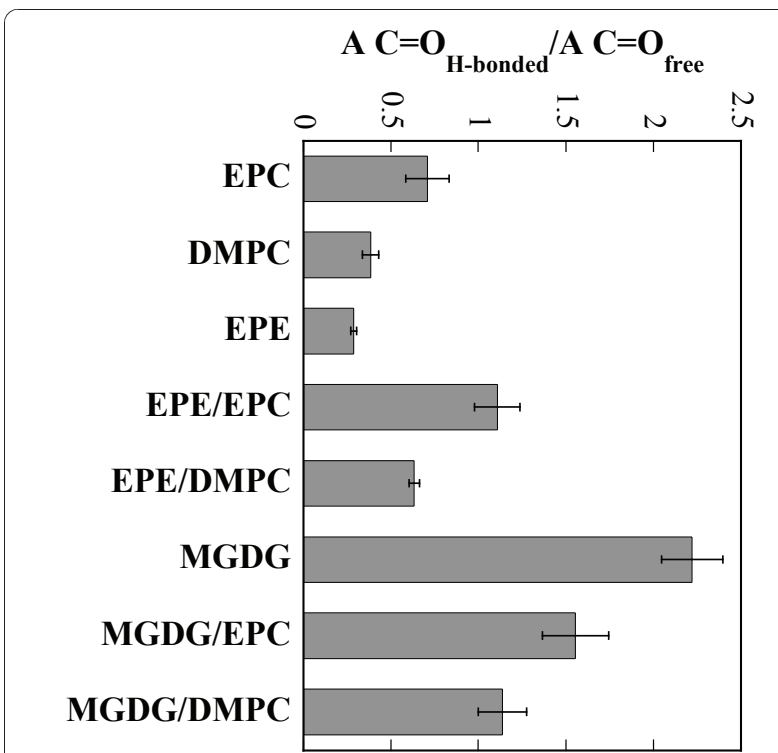

Figure 4 Ratio between the fitted peak areas of the two component bands of the carbonyl stretching peaks shown in Fig. 3. The ratio $A C=\mathrm{O}_{\text {H-bonded }} / A C=\mathrm{O}_{\text {free, }}$ indicating the relative amount of $\mathrm{H}$-bonding to the lipid $\mathrm{C}=\mathrm{O}$ groups, is shown for the pure lipids and all binary mixtures. The values represent the means \pm SE from at least 3 different samples. 
pronounced than in EPC due to the tighter packing of lipids containing only saturated acyl chains.

The ethanolamine headgroup of EPE is strongly involved in $\mathrm{H}$-bonding with $\mathrm{P}=\mathrm{O}$ groups $([9,54]$ and our results below) and is therefore shielded from the $\mathrm{C}=\mathrm{O}$ groups that are situated deeper in the bilayer. Consequently, the ratio $\mathrm{A} C=\mathrm{O}_{\mathrm{H}-\text { bonded }} / \mathrm{A} \mathrm{C}=\mathrm{O}_{\text {free }}$ for $\mathrm{EPE}$ was even lower than that for DMPC. In EPE/EPC liposomes the ratio of $\mathrm{H}$-bonded to free $\mathrm{C}=\mathrm{O}$ groups was increased compared to both pure lipids, indicating a shift of the pattern of $\mathrm{H}$-bonding of ethanolamine groups away from the $\mathrm{P}=\mathrm{O}$ and towards the $\mathrm{C}=\mathrm{O}$ groups (compare also the analysis of the $\mathrm{P}=\mathrm{O}$ vibrations below). The same was true for EPE/DMPC, but here the ratio was lower than for EPE/EPC (0.5 compared to 1.1), again indicating reduced interactions due to packing constraints.

The $\mathrm{OH}$ groups of the galactose residues in MGDG interacted with the $\mathrm{C}=\mathrm{O}$ groups, resulting in a high ratio of $\mathrm{H}$-bonded to free $\mathrm{C}=\mathrm{O}$ groups for MGDG (Figure 4). In MGDG/EPC and MGDG/DMPC bilayers this ratio was decreased, due to the lower amount of galactose headgroups. In addition, the lower ratio in MGDG/ DMPC compared to MGDG/EPC again indicated a reduction in $\mathrm{H}$-bonding to $\mathrm{C}=\mathrm{O}$ groups due to tighter packing of the lipids in membranes containing a fully saturated lipid.

\section{The headgroup region of the phospholipids and of MGDG}

The hydrophilic part of the phospholipids used in this study contains the phosphate $(\mathrm{P}=\mathrm{O})$ and choline $(\mathrm{N}$ $\left.{ }^{+}\left(\mathrm{CH}_{3}\right)_{3}\right)$ or ethanolamine $\left(\mathrm{N}^{+} \mathrm{CH}_{3}\right)$ groups. The $\mathrm{P}=\mathrm{O}$ group is situated above the $\mathrm{C}=\mathrm{O}$ and gives rise to an asymmetric vibration in the $1300-1200 \mathrm{~cm}^{-1}$ region of the infrared spectrum. While this frequency is located at $1262 \mathrm{~cm}^{-1}$ in anhydrous PC, it can be shifted to around $1220 \mathrm{~cm}^{-1}$ upon addition of water or sugars $[17,40,52,55]$. The extent of the shift is an indicator for the number and strength of the $\mathrm{H}$-bonds.

Figure 5 shows the positions of the $\mathrm{P}=\mathrm{O}$ peaks of the dry samples. For EPC and DMPC liposomes the $\mathrm{P}=\mathrm{O}$ peak was situated at $1262 \mathrm{~cm}^{-1}$, clearly indicating that the samples in the vacuum cuvette of the FTIR spectrometer were anhydrous. For pure EPE the peak was situated at $1230 \mathrm{~cm}^{-1}$, indicating massive $\mathrm{H}$-bonding between $\mathrm{P}=\mathrm{O}$ and ethanolamine groups, in agreement with earlier reports [9]. In EPE/EPC and EPE/DMPC bilayers the $\mathrm{P}=\mathrm{O}$ peak showed an intermediate position between the pure lipids due to both a reduction in EPE content and a shift of $\mathrm{H}$-bonding of ethanolamine groups from $\mathrm{P}=\mathrm{O}$ to $\mathrm{C}=\mathrm{O}$ groups, as described above. Similar intermediate positions were observed for the $\mathrm{P}=\mathrm{O}$ peak of MGDG/ EPC and MGDG/DMPC liposomes. Obviously, no $\mathrm{P}=\mathrm{O}$

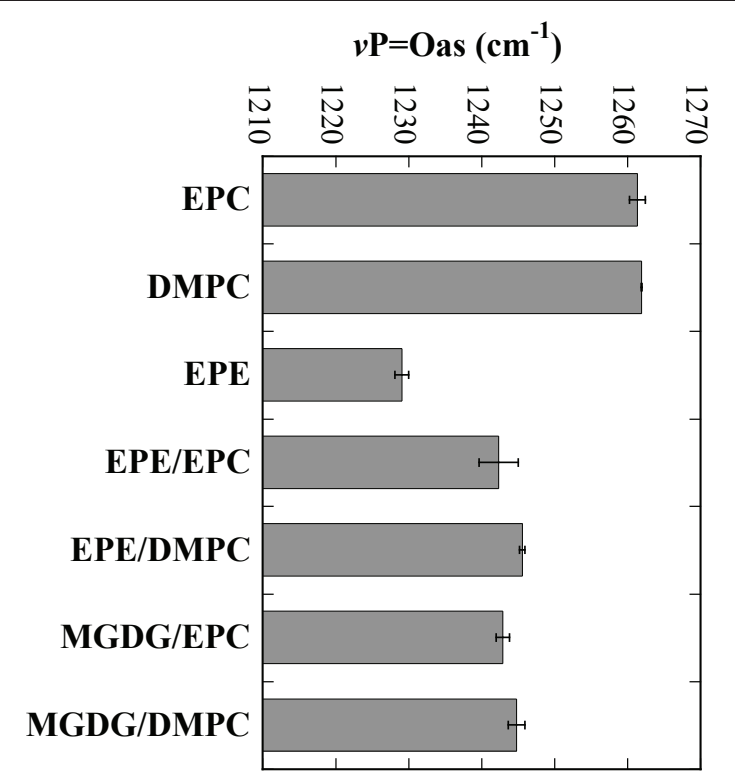

Figure $5 \mathrm{vP}=$ Oas peak positions determined from dry samples containing the indicated lipid compositions (compare Fig. 3). The values represent the means \pm SE from at least 3 different samples.

peaks were present in the spectra from pure MGDG, as this galactolipid does not contain $\mathrm{P}=\mathrm{O}$ groups. For liposomes containing $\mathrm{PC}$ and galactolipid the downfield shift of the $\mathrm{P}=\mathrm{O}$ peak position in comparison with pure EPC and DMPC could be expected, as the galactose residues in MGDG should show a similar H-bonding behavior as those in digalactosyldiacylglycerol (DGDG) $[14,56]$. Interestingly, the positions of the $\mathrm{P}=\mathrm{O}$ peaks of all mixed dry liposomes containing EPE or MGDG are very similar, indicating that the strength and/or amount of $\mathrm{H}$-bonds between $\mathrm{P}=\mathrm{O}$ groups and the ethanolamine or galactose moieties are comparable.

The terminal part of the PC headgroup is the choline group with a characteristic asymmetric stretching vibration at around $970 \mathrm{~cm}^{-1}$ which is sensitive to interactions with water $[39,57]$ and sugars $[40]$. When the choline group is involved in interactions with water its vibration is shifted upfield by a maximum of $4 \mathrm{~cm}^{-1}$ [39]. Figure 6 shows the positions of $v^{+}\left(\mathrm{CH}_{3}\right)_{3}$ as of dry liposomes containing either EPC or DMPC. The choline peak of EPC is centered at $967.5 \mathrm{~cm}^{-1}$, while for DMPC this peak is situated $1 \mathrm{~cm}^{-1}$ lower, again indicating restrictions of the interactions in more tightly packed bilayers. In all mixed liposomes the choline peak was shifted to higher wavenumbers compared to pure PC, indicating increased interactions. Similar to the $\mathrm{P}=\mathrm{O}$ peak in mixed membranes, the shift in the choline peak in the presence of EPE or MGDG was of similar magnitude. 


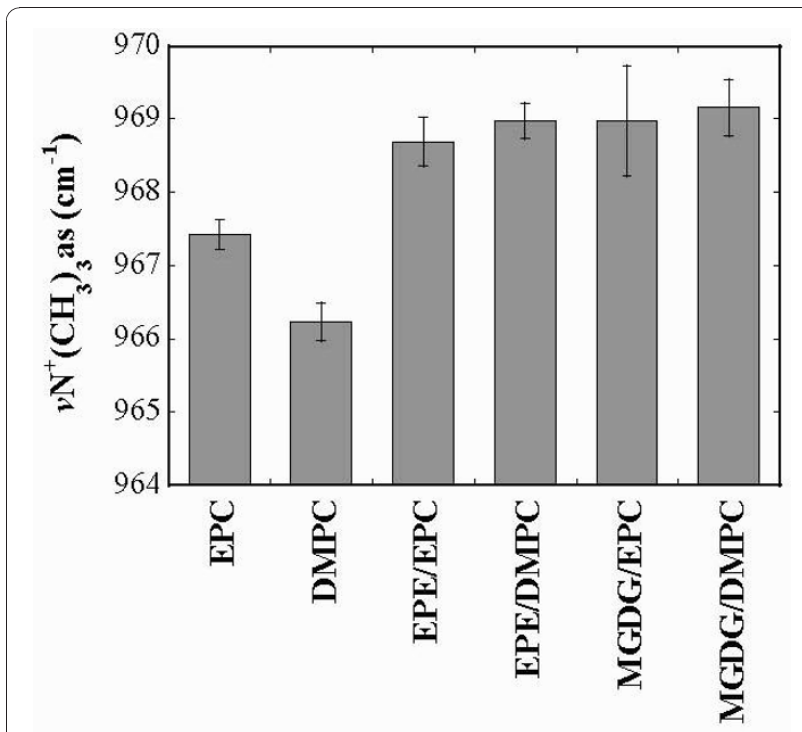

Figure $6 \mathrm{vN}^{+}\left(\mathrm{CH}_{3}\right)_{3}$ as peak positions determined from dry samples containing the indicated lipid compositions (compare Fig. 3). The values represent the means \pm SE from at least 3 different samples.

MGDG contains a galactose moiety that is able to $\mathrm{H}$ bond to other headgroups through the sugar $\mathrm{OH}$ groups. The $v \mathrm{OH}$ presents a broad peak in the FTIR spectrum from about $3600 \mathrm{~cm}^{-1}$ to $3100 \mathrm{~cm}^{-1}$ (Figure 7 ), indicating a wide variety of $\mathrm{H}$-bonding lengths and strengths. In pure, dry amorphous sucrose $\mathrm{vOH}$ is centered at $3370 \mathrm{~cm}^{-1}$ and this band is shifted to about $3320 \mathrm{~cm}^{-1}$ for sucrose fully $\mathrm{H}$-bonded to EPC membranes in the dry state $[40,58]$. In pure, dry MGDG $\mathrm{vOH}$ was centered at $3448 \mathrm{~cm}^{-1}$ (Figure 7), indicating

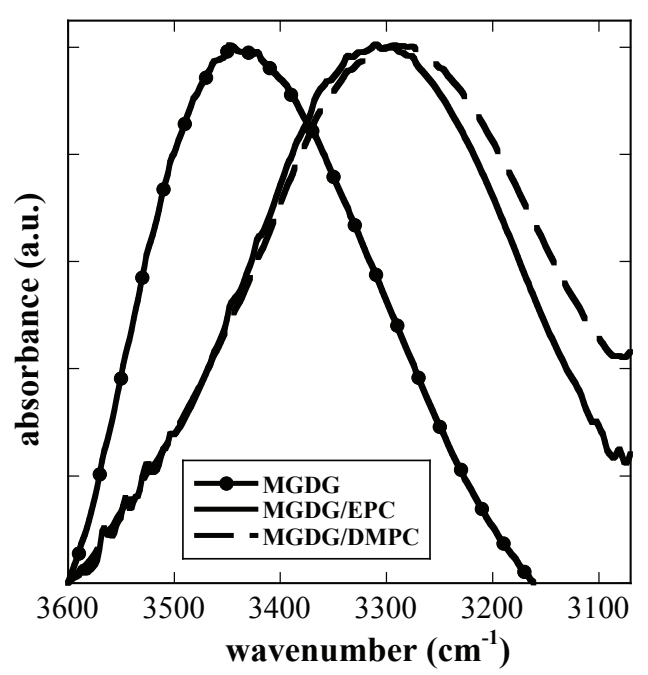

Figure 7 Infrared spectra in the $\mathrm{OH}$ stretching vibration $(\mathrm{vOH})$ region of the galactose headgroups of MGDG in pure MGDG and the indicated binary mixtures. only a low degree of $\mathrm{H}$-bonding between MGDG molecules. In membranes containing $50 \%$ of either EPC or $\mathrm{DMPC}, v \mathrm{OH}$ was shifted by more that 100 wavenumbers to around $3310 \mathrm{~cm}^{-1}$, emphasizing the strong intermolecular H-bonding between MGDG and PC noted above (Figure 4 and 5). The exceptional strength of these bonds is also indicated by the complete absence of a temperature dependence in $\mathrm{vOH}$ in the mixed membranes, while the low level of $\mathrm{H}$-bonding in pure MGDG was further decreased at higher temperatures (Figure 8).

\section{Discussion}

In the present paper we used both FTIR spectroscopy and DSC to determine the phase behavior and the molecular interactions of bilayer and nonbilayer lipids. This combination was necessary, as none of the methods alone would have yielded a complete picture of these dry lipid systems. The position of the $v \mathrm{CH}_{2} \mathrm{~s}$ peak in FTIR spectra is sensitive to the mobility of the fatty acyl chains and can thus be used to discriminate between lipids in the gel state and lipids in either the liquid-crystalline or nonlamellar state [43]. Consequently, only transitions between gel phase and either of the other two phases were detected, but not transitions from liquid-crystalline to nonlamellar. In addition to the gel phase, fully saturated lipids such as DMPC can also form a solid (crystalline) phase $[59,60]$. However, we found no evidence of an additional low-temperature phase transition in either the FTIR or DSC data. In DSC thermograms gel to liquid-crystalline and liquid-crystalline to nonlamellar transitions can be easily distinguished due to the large difference in transition enthalpy [7]. However,

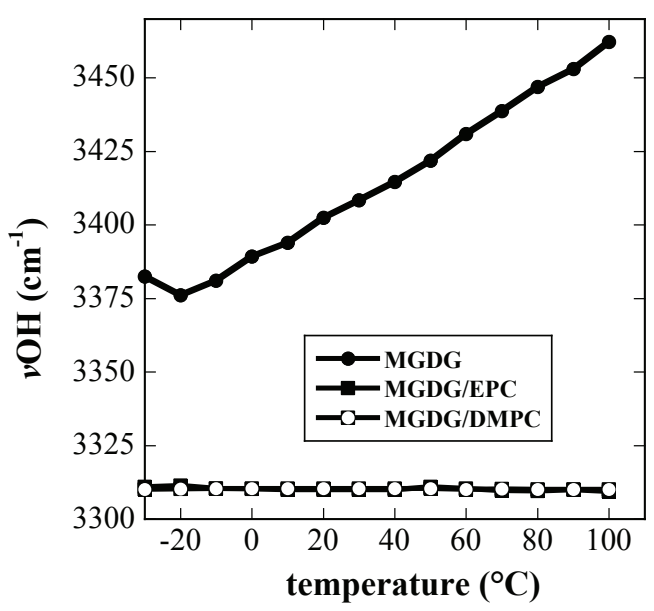

Figure $8 \mathrm{vOH}$ of the galactose headgroups of MGDG in pure MGDG and in the indicated binary mixtures (compare Fig. 7) as a function of temperature. The peak positions determined from the two binary mixtures were almost identical at all temperatures and therefore only the symbols for one lipid composition are visible. 
with DSC interactions between lipid molecules can not be detected, making a combination of these two methods especially useful for the characterization of interactions between lipids and between lipids and interacting solutes or proteins. It should, however, be noted that neither method allows absolute phase assignments, but only records transitions between phases.

Pure, dry EPE showed one phase transition in the FTIR, corresponding to a gel to liquid-crystalline transition and an additional low enthalpy transition to $\mathrm{H}_{\mathrm{II}}$ was detected by DSC. This sequence of transitions has also been reported for different PEs in the hydrated state [20,61-63]. The $T_{m}$ for pure EPE was significantly lower than that determined by DSC for pure dry POPE $\left(73^{\circ} \mathrm{C},[60]\right)$. In addition, the same $\mathrm{T}_{\mathrm{m}}$ was found for dry POPE and POPC, while we found a large difference in the $\mathrm{T}_{\mathrm{m}}$ of dry EPE and EPC. These differences have to be attributed to the different fatty acid composition of the lipids, as EPE and EPC are not composed of identical fatty acids (compare Methods section).

Due to the high degree of unsaturation of the fatty acyl chains of the MGDG from spinach leaves used in this study and the resultant high mobility of the chains, $v \mathrm{CH}_{2} \mathrm{~S}$ was located at high wavenumbers (above 2854 $\mathrm{cm}^{-1}$ ) even at $-30^{\circ} \mathrm{C}$ and there was no indication for a phase transition in the FTIR data. There was only one low enthalpy phase transition apparent in the DSC thermograms, indicating that dry MGDG was in the liquidcrystalline phase at low temperature and in a nonlamellar phase at high temperature. For fully hydrated MGDG previous DSC measurements have shown a transition from $\mathrm{H}_{\mathrm{II}}$ to lamellar phase at $-30^{\circ} \mathrm{C}$ during cooling [26] and a lamellar to $\mathrm{H}_{\mathrm{II}}$ transition at $-44^{\circ} \mathrm{C}$ during heating [16].

In all mixed bilayer systems (EPE/EPC, EPE/DMPC, MGDG/EPC, MGDG/DMPC) only gel to liquid-crystalline phase transitions were detected by FTIR and DSC, while the DSC thermograms indicated that the transition from liquid-crystalline to nonbilayer was completely abolished. As expected, $\mathrm{T}_{\mathrm{m}}$ was significantly higher in membranes containing DMPC than in those containing EPC. Only in the case of MGDG/DMPC membranes, there was an indication for a partial demixing of the two lipids during the phase transition. This was only apparent in the DSC thermograms, where two peaks were resolved, but not in the FTIR melting curves that only showed one transition. We have shown previously that the resolution of more than one lipid melting event is possible with our FTIR method [53]. This suggests that the more unsaturated MGDG started to melt at a lower temperature than DMPC, but that the two melting events were too close together to be resolved by FTIR. In the liquid-crystalline state, the two lipids were completely mixed again, thereby preventing a further transition to $\mathrm{H}_{\mathrm{II}}$, that was observed in pure MGDG. Interestingly, EPE/EPC membranes showed a phase transition that was almost identical to that of EPE (and not halfway between EPE and EPC), indicating the importance of headgroup interactions for the phase behavior of this lipid mixture.

In the fully hydrated state it has been shown previously for MGDG/DMPC [64], EPE/EPC, DOPE/DOPC [22] and DMPC/DMPE [11] that stable bilayers were formed, where the two lipids were well mixed and did not form separate domains. On the other hand, it has been suggested that during dehydration, when the formation of nonlamellar structures is favoured, phase separation of lipids with different phase preferences can take place, leading to freezing and dehydration induced membrane damage $[32,65]$. The results presented here suggest that for the investigated lipid mixtures such phase separation and $\mathrm{H}_{\mathrm{II}}$ formation did not occur during drying.

FTIR has provided evidence for complex interactions between lipid headgroups in the dry state that was observed at the $\mathrm{C}=\mathrm{O}$ (all lipids), $\mathrm{P}=\mathrm{O}$ (EPE, EPC, DMPC), choline (EPC, DMPC) and sugar OH (MGDG) levels. These interactions are made possible by the strong tilt of the headgroups in PC [66] and PE [67] towards the membrane surface in the hydrated state, which is increased during dehydration, as shown for PC [68]. For MGDG, some results also suggest a headgroup orientation almost parallel to the surface of the lipid bilayer [28], while other studies indicated that $\beta$-anomeric linkages of monosacharides, as in MGDG, lead to an orientation of the sugar away from the surface of fully hydrated membranes [69]. The strong involvement of the MGDG headgroup in $\mathrm{H}$-bonding interactions that we found in the present study indicates that at least in the dry state the headgroup is bent towards the membrane surface, similar to the DGDG headgroup [70]. A comparison of the interaction patterns of the different functional groups across all relevant lipid combinations yielded results consistent with this assumption.

The ethanolamine in PE has been shown previously to form a network of strong $\mathrm{H}$-bonds and electrostatic interactions with $\mathrm{P}=\mathrm{O}$ groups $[9,63,71]$. These interactions result in a relatively low frequency of the $v \mathrm{P}=\mathrm{Oas}$ vibration compared to $\mathrm{PC}$. In the dry state $v \mathrm{P}=\mathrm{O}$ as of DMPC is situated at $1262 \mathrm{~cm}^{-1}$, while in the fully hydrated state it is shifted to around $1220 \mathrm{~cm}^{-1}$ [52]. For hydrated DMPE the frequency of the $\mathrm{P}=\mathrm{O}$ vibration was found at $1217 \mathrm{~cm}^{-1}$ [72,73], while for dry PE values between $1231 \mathrm{~cm}^{-1}$ and $1234 \mathrm{~cm}^{-1}$ [74] were reported, in good agreement with the value of $1230 \mathrm{~cm}^{-1}$ measured here for EPE.

The $v \mathrm{P}=\mathrm{O}$ as of mixed membranes containing EPE/ EPC or EPE/DMPC had intermediate positions, in 
agreement with recent data on hydrated EPE/EPC mixtures [11]. The spectra also indicate that the interactions of ethanolamine groups were limited to the $\mathrm{P}=\mathrm{O}$ groups and that access to the $\mathrm{C}=\mathrm{O}$ groups was strongly restricted. This was reflected in the position of the $\mathrm{C}=\mathrm{O}$ peak, which was highest in pure EPE and in the $\mathrm{A}$ $\mathrm{C}=\mathrm{O}_{\mathrm{H} \text {-bonded }} / \mathrm{A} \mathrm{C}=\mathrm{O}_{\text {free }}$ ratio, which also showed the lowest value for pure EPE. In the mixed membranes, this ratio increased, indicating increased $\mathrm{H}$-bonding of the ethanolamine groups to the $\mathrm{C}=\mathrm{O}$ groups with a concomitant decrease in the interactions with the $\mathrm{P}=\mathrm{O}$ groups. A similar increase was also observed in $\mathrm{H}$-bonding to the choline groups, in agreement with a general redistribution of the interaction pattern between pure EPE and EPE/EPC mixtures. $\mathrm{H}$-bonding to the $\mathrm{C}=\mathrm{O}$ groups was strikingly lower in membranes containing DMPC than in those containing EPC, indicating that the tight packing of the membranes in the presence of a fully saturated lipid restricted access of other groups to the $\mathrm{C}=\mathrm{O}$ moieties.

The $\mathrm{OH}$ groups in the galactose headgroup of MGDG $\mathrm{H}$-bond effectively to the $\mathrm{C}=\mathrm{O}, \mathrm{P}=\mathrm{O}$ and choline groups. In pure MGDG the fraction of $\mathrm{C}=\mathrm{O}$ groups involved in $\mathrm{H}$-bonding was more than twice that of free $\mathrm{C}=\mathrm{O}$ and also the mixtures with $\mathrm{PCs}$ showed high $\mathrm{A} \mathrm{C}=\mathrm{O}_{\mathrm{H}-\text { bonded }} /$ A $\mathrm{C}=\mathrm{O}_{\text {free }}$ ratios. Similarly, these mixtures showed reduced $v \mathrm{P}=\mathrm{O}$ as and increased $v \mathrm{~N}^{+}\left(\mathrm{CH}_{3}\right)_{3}$ as values in comparison to pure EPC and DMPC, indicating $\mathrm{H}$ bonding with the galactose $\mathrm{OH}$ groups. Additional evidence for these $\mathrm{H}$-bonding interactions was found in the massive shift of the $v \mathrm{OH}$ vibration by more than 100 wavenumbers in the mixed membranes compared to pure MGDG. A similar pattern of $\mathrm{H}$-bonding has previously been shown in dry samples of mixed EPC/ DGDG liposomes [39].

While the $\mathrm{H}$-bonding with the $\mathrm{C}=\mathrm{O}$ groups in the mixed membranes was always weaker in the presence of DMPC than in the presence of EPC, the degree of lipid unsaturation was less important for interactions with the $\mathrm{P}=\mathrm{O}$ groups. The phosphate group is situated further away from the hydrophobic core of the membrane than the carbonyl esters and therefore the packing of the acyl chains and the area per lipid molecule have less influence on the degree of interaction.

\section{Conclusions}

We have provided a comprehensive characterization of dry membrane systems containing two biologically important nonbilayer lipids that will help in the future to evaluate mechanisms and consequences of the interactions of solutes and proteins that may be involved in cellular desiccation tolerance. In particular, the detailed FTIR analyses of the interfacial and headgroup regions of these membrane systems will enable a detailed understanding of the mode of action of such protective molecules that may play crucial roles in anhydrobiosis [75], still one of the most enigmatic phenomena in biology.

\section{Acknowledgements}

We are grateful to Dr. Klaus Tauer (Max-Planck-Institute of Colloids and Interfaces, Potsdam, Germany) for making the DSC facilities available and to Irina Shekova for excellent technical assistance.

\section{Author details}

${ }^{1}$ Max-Planck-Institut für Molekulare Pflanzenphysiologie, Am Mühlenberg 1, D-14476 Potsdam, Germany. ${ }^{2}$ Institute of Biophysics, Bulgarian Academy of Sciences, 1113 Sofia, Bulgaria.

\section{Authors' contributions}

AVP designed and conducted all experiments, analyzed the data and drafted the manuscript. DKH participated in experimental design and data analysis, and wrote the final manuscript. Both authors read and approved the final manuscript.

Received: 1 March 2011 Accepted: 10 May 2011 Published: 10 May 2011

\section{References}

1. Cullis PR, Hope MJ, Tilcock CPS: Lipid polymorphism and the roles of lipids in membranes. Chem Phys Lipids 1986, 40:127-144.

2. Tilcock CPS: Lipid polymorphism. Chem Phys Lipids 1986, 40:109-125.

3. Kuzmin PI, Zimmerberg J, Chizmadzhev YA, Cohen FS: A quantitative model for membrane fusion based on low-energy intermediates. Proc Natl Acad Sci USA 2001, 98:7235-7240

4. Siegel DP: The modified stalk mechanism of lamellar/inverted phase transitions and its implications for membrane fusion. Biophys J 1999, 76:291-313.

5. Epand RM: Functional roles of non-lamellar forming lipids. Chem Phys Lipids 1996, 81:101-104

6. Mclntosh TJ: Hydration properties of lamellar and non-lamellar phases of phosphatidylcholine and phosphatidylethanolamine. Chem Phys Lipids 1996, 81:117-131.

7. Seddon JM: Structure of the inverted hexagonal $\left(\mathrm{H}_{\|}\right)$phase, and nonlamellar phase transitions of lipids. Biochim Biophys Acta 1990, 1031:1-69.

8. Kinnunen PKJ: On the molecular-level mechanisms of peripheral proteinmembrane interactions induced by lipids forming inverted non-lamellar phases. Chem Phys Lipids 1996, 81:151-166.

9. Lewis RNAH, McElhaney RN: Calorimetric and spectroscopic studies of the polymorphic phase behavior of a homologous series of n-saturated 1,2diacyl phosphatidylethanolamines. Biophys J 1993, 64:1081-1096.

10. Lindblom G, Rilfors $L$ : Nonlamellar phases formed by membrane lipids. Adv Coll Interface Sci 1992, 41:101-125.

11. Bouchet AM, Frias MA, Lairion F, Martini F, Almaleck H, Gordillo G, Disalvo EA: Structural and dynamical surface properties of phosphatidylethanolamine containing membranes. Biochim Biophys Acta 2009, 1788:918-925

12. Crowe $\mathrm{JH}$, Crowe LM, Carpenter JF, Rudolph AS, Aurell Wistrom C, Spargo BJ, Anchordoguy TJ: Interaction of sugars with membranes. Biochim Biophys Acta 1988, 947:367-384

13. Crowe JH, Hoekstra FA, Crowe LM: Anhydrobiosis. Annu Rev Physiol 1992, 54:579-599.

14. Hincha DK, Popova AV, Cacela C: Effects of sugars on the stability of lipid membranes during drying. In Advances in Planar Lipid Bilayers and Liposomes. Volume 3. Edited by: Leitmannova Liu A. Amsterdam: Elsevier; 2006:189-217.

15. Hincha DK, Oliver AE, Crowe JH: Lipid composition determines the effects of arbutin on the stability of membranes. Biophys J 1999, 77:2024-2034.

16. Oliver AE, Hincha DK, Tsvetkova NM, Vigh L, Crowe JH: The effect of arbutin on membrane integrity during drying is mediated by stabilization of the lamellar phase in the presence of nonbilayer-forming lipids. Chem Phys Lipids 2001, 111:37-57.

17. Popova AV, Hincha DK: Specific interactions of tryptophan with phosphatidylcholine and digalactosyldiacylglycerol in pure and mixed 
bilayers in the dry and hydrated state. Chem Phys Lipids 2004 132:171-184.

18. Thalhammer A, Hundertmark M, Popova AV, Seckler R, Hincha DK Interaction of two intrinsically disordered plant stress proteins (COR15A and (OR15B) with lipid membranes in the dry state. Biochim Biophys Acta 2010, 1798:1812-1820

19. Tolleter D, Hincha DK, Macherel D: A mitochondrial late embryogenesis abundant protein stabilizes model membranes in the dry state. Biochim Biophys Acta 2010, 1798:1926-1933.

20. Cullis PR, de Kruijff B: Lipid polymorphism and the functional roles of lipids in biological membranes. Biochim Biophys Acta 1979, 559:399-420.

21. Gawrisch K, Holte LL: NMR investigations of non-lamellar phase promoters in the lamellar phase state. Chem Phys Lipids 1996, 81:105-116.

22. Webb MS, Hui SW, Steponkus PL: Dehydration-induced lamellar-tohexagonal-II phase transitions in DOPE/DOPC mixtures. Biochim Biophys Acta 1993, 1145:93-104.

23. Dörmann P, Benning C: Galactolipids rule in seed plants. Trends Plant Sci 2002, 7:112-118

24. Quinn PJ, Williams WP: The structural role of lipids in photosynthetic membranes. Biochim Biophys Acta 1983, 737:223-266.

25. Webb MS, Green BR: Biochemical and biophysical properties of thylakoid acyl lipids. Biochim Biophys Acta 1991, 1060:133-158.

26. Shipley GG, Green JP, Nichols BW: The phase behaviour of monogalactosyl, digalactosyl, and sulphoquinovosyl diglycerides. Biochim Biophys Acta 1973, 311:531-544.

27. Sanderson PW, Williams WP: Low-temperature phase behaviour of the major plant leaf lipid monogalactosyldiacylglycerol. Biochim Biophys Acta 1992, 1107:77-85.

28. Bottier C, Gean J, Artzner F, Desbat B, Pezolet M, Renault A, Marion D, Vie V: Galactosyl headgroup interactions control the molecular packing of wheat lipids in Langmuir films and in hydrated liquid-crystalline mesophases. Biochim Biophys Acta 2007, 1768:1526-1540.

29. Chupin $V$, van't Hof $R$, de Kruijff B: The transit sequence of a chloroplast precursor protein reorients the lipids in monogalactosyl diglyceride containing bilayers. FEBS Lett 1994, 150:104-108.

30. Hincha DK, Oliver AE, Crowe JH: The effects of chloroplast lipids on the stability of liposomes during freezing and drying. Biochim Biophys Acta 1998, 1368:150-160.

31. Caffrey M: Kinetics and mechanism of the lamellar gel/lamellar liquidcrystal and lamellar/inverted hexagonal phase transition in phosphatidylethanolamine: a real-time X-ray diffraction study using synchrotron radiation. Biochemistry 1985, 24:4826-4844.

32. Crowe $\mathrm{JH}$, Crowe LM, Mouradian R: Stabilization of biological membranes at low water activities. Cryobiology 1983, 20:346-356.

33. Marrink S-J, Mark AE: Molecular view of hexagonal phase formation in phospholipid membranes. Biophys J 2004, 87:3894-3900.

34. Bradshaw JP, Edenborough MS, Sizer PJH, Watts A: A description of the phospholipid arrangement intermediate to the humidity produced $\mathrm{L}_{c}$ and $H_{\|}$phases in dioleoylphosphatidylcholine and its modification by dioleoylphosphatidylethanolamine as studied by X-ray diffraction. Biochim Biophys Acta 1989, 987:104-110

35. Gounaris K, Sen A, Brain APR, Quinn PJ, Williams WP: The formation of non-bilayer structures in total polar lipid extracts of chloroplast membranes. Biochim Biophys Acta 1983, 728:129-139.

36. Mannock DA, McElhaney RN: Thermotropic and lyotropic phase properties of glycolipid diastereomers: role of headgroup and interfacial interactions in determining phase behavior. Curr Opin Colloid Interface Sci 2004, 8:426-447.

37. MacDonald RC, MacDonald RI, Menco BPM, Takeshita K, Subbarao NK, Hu L: Small-volume extrusion apparatus for preparation of large, unilamellar vesicles. Biochim Biophys Acta 1991, 1061:297-303.

38. Hincha DK, Zuther E, Hellwege EM, Heyer AG: Specific effects of fructoand gluco-oligosaccharides in the preservation of liposomes during drying. Glycobiology 2002, 12:103-110

39. Popova AV, Hincha DK: Intermolecular interactions in dry and rehydrated pure and mixed bilayers of phosphatidylcholine and digalactosyldiacylglycerol: a Fourier-transform infrared spectroscopy study. Biophys J 2003, 85:1682-1690.

40. Cacela C, Hincha DK: Low amounts of sucrose are sufficient to depress the phase transition temperature of dry phosphatidylcholine, but not for lyoprotection of liposomes. Biophys J 2006, 90:2831-2842.
41. Crowe JH, Oliver AE, Hoekstra FA, Crowe LM: Stabilization of dry membranes by mixtures of hydroxyethyl starch and glucose: the role of vitrification. Cryobiology 1997, 35:20-30

42. Popova AV, Hincha DK: Effects of cholesterol on dry bilayers: interactions between phosphatidylcholine unsaturation and glycolopid or free sugar. Biophys J 2007, 93:1204-1214

43. Mantsch HH, McElhaney RN: Phospholipid phase transitions in model and biological membranes as studied by infrared spectroscopy. Chem Phys Lipids 1991, 57:213-226.

44. Aurell Wistrom C, Rand RP, Crowe LM, Spargo BJ, Crowe JH: Direct transition of dioleoylphosphatidylethanolamine from lamellar gel to inverted hexagonal phase caused by trehalose. Biochim Biophys Acta 1989, 984:238-242

45. Epand RM: Hydrogen bonding and the thermotropic transitions of phosphatidylethanolamines. Chem Phys Lipids 1990, 52:227-230.

46. Hinz $\mathrm{H}-J$, Kuttenreich $\mathrm{H}$, Meyer $\mathrm{R}$, Renner M, Fründ R, Koynova R, Boyanov Al, Tenchov BG: Stereochemistry and size of sugar head groups determine structure and phase behavior of glycolipid membranes: densitometric, calorimetric, and x-ray studies. Biochemistry 1991 30:5125-5138.

47. Howe J, von Minden M, Gutsmann T, Koch MHJ, Wulf M, Gerber S, Milkereit G, Vill V. Brandenburg K: Structural preferences of dioleoyl glycolipids with mono- and disaccharide head groups. Chem Phys Lipids 2007, 149:52-58

48. Sen A, Hui S-W, Mannock DA, Lewis RNAH, McElhaney RN: Physical properties of glycosyl diacylglycerols. 2. X-ray diffraction studies of a homologous series of 1,2-di-O-acyl-3-O-(a-D-glucopyranosyl)-sn-glycerols. Biochemistry 1990, 29:7799-7804

49. Turner DC, Wang Z-G, Gruner SM, Mannock DA, McElhaney RN: Structural study of the inverted cubic phases of di-dodecyl alkyl- $\beta-D$ glucopyranosyl-rac-glycerol. J Phys II 1992, 2:2039-2063.

50. Blume A, Hübner W, Messner G: Fourier transform infrared spectroscopy of ${ }^{13} \mathrm{C}=\mathrm{O}$-labeled phospholipids. Hydrogen bonding to carbonyl groups. Biochemistry 1988, 27:8239-8249.

51. Lewis RNAH, McElhaney RN: Fourier transform infrared spectroscopy in the study of hydrated lipids and lipid bilayer membranes. In Infrared Spectroscopy of Biomolecules. Edited by: Mantsch HH, Chapman D. New York: Wiley-Liss; 1996:159-202

52. Wong PTT, Mantsch $\mathrm{HH}$ : High-pressure infrared spectroscopic evidence of water binding sites in 1,2-diacyl phospholipids. Chem Phys Lipids 1988 46:213-224.

53. Cacela C, Hincha DK: Monosaccharide composition, chain length and linkage type influence the interactions of oligosaccharides with dry phosphatidylcholine membranes. Biochim Biophys Acta 2006, 1758:680-691.

54. Seu KJ, Cambrea LR, Everly ME, Hovis JS: Influence of lipid chemistry on membrane fluidity: tail and headgroup interactions. Biophys J 2006, 91:3727-3735.

55. Lewis RNAH, McElhaney RN: The structure and organization of phospholipid bilayers as revealed by infrared spectroscopy. Chem Phys Lipids 1998, 96:9-21.

56. Popova AV, Hincha DK: Effects of the sugar headgroup of a glycoglycerolipid on the phase behavior of phospholipid model membranes in the dry state. Glycobiology 2005, 15:1150-1155.

57. Akutsu H: Direct determination by Raman scattering of the conformation of the choline group in phospholipid bilayers. Biochemistry 1981, 20:7359-7366

58. Buitink J, van den Dries IJ, Hoekstra FA, Alberda M, Hemminga MA: High critical temperature above $\mathrm{T}_{\mathrm{g}}$ may contribute to the stability of biological systems. Biophys J 2000, 79:1119-1128.

59. Pearson RH, Pascher I: The molecular structure of lecithin dihydrate. Nature 1979, 281:499-501.

60. Mansour HM, Zografi G: The relationship between water vapor absorption and desorption by phospholipids and bilayer phase transitions. J Pharm Sci 2007, 96:377-396.

61. Mantsch HH, Martin A, Cameron DG: Characterization by infrared spectroscopy of the bilayer to nonbilayer phase transition of phosphatidylethanolamines. Biochemistry 1981, 20:3138-3145.

62. Rappolt M, Hickel A, Bringezu F, Lohner K: Mechanism of the lamellar/ inverse hexagonal phase transition examined by high resolution $\mathrm{X}$-ray diffraction. Biophys J 2003, 84:3111-3122. 
63. Seddon JM, Cevc G, Kaye RD, Marsh D: X-ray diffraction study of the polymorphism of hydrated diacyl- and

dialkylphosphatidylethanolamines. Biochemistry 1984, 24:2634-2644.

64. Castro V, Dvinskikh SV, Widmalm G, Sandström D, Maliniak A: NMR studies of membranes composed of glycolipids and phospholipids. Biochim Biophys Acta 2007, 1768:2432-2437.

65. Cudd A, Steponkus PL: Lamellar-to hexagonal $\mathrm{H}_{\|}$phase transitions in liposomes of rye plasma membrane lipids after osmotic dehydration. Biochim Biophys Acta 1988, 941:278-286.

66. Büldt G, Gally HU, Seelig J: Neutron diffraction studies on phosphatidylcholine model membranes. I. Head group conformation. J Mol Biol 1979, 134:673-691.

67. Pascher I, Lundmark M, Nyholm P-G, Sundell S: Crystal structure of membrane lipids. Biochim Biophys Acta 1992, 1113:339-373.

68. Mashl RJ, Scott HL, Subramaniam S, Jacobsson E: Molecular simulation of dioleoylphosphatidylcholine lipid bilayers at differing levels of hydration Biophys J 2001, 81:3005-3015

69. Mannock DA, Lewis RNAH, McElhaney RN: Physical properties of glycosyl diacylglycerols. 1. Calorimetric studies of a homologous series of 1,2-diO-acyl-3-O-(a-D-glucopyranosyl)-sn-glycerols. Biochemistry 1990, 29:7790-7799.

70. McDaniel RV: Neutron diffraction studies of digalactosyldiacylglycerol. Biochim Biophys Acta 1988, 940:158-164.

71. Hauser $\mathrm{H}$, Pascher I, Pearson RH, Sundell S: Preferred conformation and molecular packing of phosphatidylethanolamine and phosphatidylcholine. Biochim Biophys Acta 1981, 650:21-51.

72. Pohle W, Selle C, Fritzsche H, Bohl M: Comparative FTIR spectroscopic study upon the hydration of lecithins and cephalins. J Mol Struct 1997, 408/409:273-277.

73. Hübner W, Blume A: Interactions at the lipid-water interface. Chem Phys Lipids 1998, 96:99-123.

74. Pohle W, Selle C: Fourier-transform infrared spectroscopic evidence for a novel lyotropic phase transition occurring in dioleoylphosphatidylethanolamine. Chem Phys Lipids 1996, 82:191-198.

75. Oliver AE, Leprince O, Wolkers WF, Hincha DK, Heyer AG, Crowe JH: Nondisaccharide-based mechanisms of protection during drying. Cryobiology 2001, 43:151-167.

doi:10.1186/2046-1682-4-11

Cite this article as: Popova and Hincha: Thermotropic phase behavior and headgroup interactions of the nonbilayer lipids

phosphatidylethanolamine and monogalactosyldiacylglycerol in the dry state. BMC Biophysics 2011 4:11

\section{Submit your next manuscript to BioMed Central and take full advantage of:}

- Convenient online submission

- Thorough peer review

- No space constraints or color figure charges

- Immediate publication on acceptance

- Inclusion in PubMed, CAS, Scopus and Google Scholar

- Research which is freely available for redistribution 